\title{
Kreativitas serta Tradisi dan Inovasi dalam Pendidikan Arsitektur
}

\author{
Adi Utomo Hatmoko \\ Departemen Teknik Arsitektur dan Perencanaan, Fakultas Teknik, Universitas Gadjah Mada \\ Email: adiutomohatmoko@yahoo.com
}

\begin{abstract}
Abstrak
Pendidikan S-1 arsitektur kita secara umum berorientasi pada pendidikan profesional, dan bukannya pendidikan akademik. Pendidikan profesional ini berawal dari tradisi bengkel dan ketrampilan, di samping banyak dipengaruhi oleh dunia seni dan budaya. Oleh karena itu banyak dicirikan oleh adanya trial and error yang disebabkan karena permasalahannya bersifat liar (wicked) dan bukannya jinak (tame). Pendidikan profesional dengan sentuhan seni yang bersifat liar ini akan sangat membutuhkan adanya interaksi antara termagang (master) dan pemagang (apprentice) yang sangat erat. Karena dari sistem inilah perpindahan ketrampilan dan pengetahuan akan berpindah secara efektif. Kualitas rancangan pada dasarnya dapat ditingkatkan dengan mempelajari preseden (precedents, karya arsitektur yang sudah ada dan dianggap berhasil) dan pemahaman yang lebih jauh mengenai prinsip-prinsip yang melandasi karya arsitektur tersebut (principles, gagasan-gagasan mengenai aspek-aspek yang menjadikan karya arsitektur berhasil dan mengenai implikasi guna dan citra terhadap karya arsitektur tersebut). Sebagaimana para seniman kreatif lainnya, para arsitek menggunakan beberapa strategi yang lazim mereka lakukan dari waktu ke waktu. Mereka belajar melalui pengalaman, menyerap pelajaran pada tiap kasus perancangan, sehingga karya yang belakangan akan terpengaruh oleh karya-karya terdahulu. Menggambarkan ulang dan meniru karya sang pakar secara sadar merupakan suatu tahap yang penting disini. Setelah memperhatikan dan meniru, diharapkan sang pemula dapat secara sadar menemukan prinsip-prinsip yang mendasari karya sang pakar tersebut. Pada akhirnya diharapkan sang pemula tersebut pada suatu saat dapat berkarya dengan strategi yang lebih sesuai dengan kemampuan dan kehendaknya. Tantangan kita sekarang, adalah bagaimana hal-hal tersebut dapat dilakukan dengan baik, sementara interaksi dosen dan mahasiswa, termagang dan pemagang, menjadi terbatas karena adanya pandemi.
\end{abstract}

Kata kunci: pendidikan arsitektur, kreativitas, tradisi, inovasi.

\section{Abstract \\ Title: Creativity with Tradition and Innovation in Architectural Education}

Our undergraduate architecture education is generally oriented towards professional education, and not academic education. This professional education originated from the tradition of workshops and skills, in addition to being heavily influenced by the world of art and culture. Therefore, many are characterized by the existence of trial and error caused because the problem is wicked rather than tame. Professional education with a touch of art that is wild will really need a very close interaction between the master and apprentice. Because of this system, the transfer of skills and knowledge will move effectively. The quality of the design can basically be improved by studying precedents (architectural works that already exist and are considered successful) and a further understanding of the principles underlying the architectural work (principles, ideas about aspects that make architectural works successful). Regarding the implications of use and image for the architectural work). Like other creative artists, architects use some strategies that they are accustomed to from time to time. They learn through experience, absorbing lessons from each design case, so that later works will be influenced by previous works. Redrawing and imitating the master's work consciously is an important step here. After observing and imitating, it is hoped that the beginner can consciously discover the principles that underlie the work of the expert. In the end, it is hoped that the beginner will someday be able to work with a strategy that is more in line with his 
abilities and wishes. Now, our challenge is how these things can be done well, while the interaction of lecturers and students, apprentices and apprentices, is limited due to the pandemic.

Keywords: architectural education, creativity, tradition, innovation.

\section{Pendahuluan}

Pendidikan S-1 arsitektur kita secara umum berorientasi pada pendidikan profesional, dan bukannya pendidikan akademik. Pendidikan profesional ini berawal dari tradisi bengkel dan ketrampilan, di samping banyak dipengaruhi oleh dunia seni dan budaya. Oleh karena itu banyak dicirikan oleh adanya trial and error yang disebabkan karena permasalahannya bersifat liar (wicked) dan bukannya jinak (tame). Pendidikan profesional dengan sentuhan seni yang bersifat liar ini akan sangat membutuhkan adanya interaksi antara termagang (master) dan pemagang (apprentice) yang sangat erat. Karena dari sistem inilah perpindahan ketrampilan dan pengetahuan akan berpindah secara efektif.

Harus diakui bahwa tidak semua staf pengajar di perguruan tinggi arsitektur adalah termagang (master) yang baik, dalam arti telah memiliki kuantitas dan kualitas karya yang didukung oleh integritas konsep yang tinggi. Untuk itu, dibutuhkan metode dan teknik yang dapat memungkinkan para mahasiswa sebagai pemagang (apprentice) dapat mencari model yang dapat digunakannya untuk memecahkan masalah-masalah arsitektur.

Pengalaman mendidik di Departemen Arsitektur FT-UGM membuktikan bahwa pendidik dapat berperan sebagai fasilitator disamping sebagai master. Untuk itu dibutuhkan perluasan cakrawala melalui analisis dan pengenalan banyak contohcontoh karya, baik melalui literatur maupun melalui penghayatan lapangan. Pendidik juga dapat berperan sebagai mediator antara master arsitek yang bersifat maya (para tokoh dunia arsitektur yang dapat dipelajari karyanya) dengan para mahasiswanya. Contoh-contoh dari studio perancangan dapat menjelaskan metodametoda dan teknik-teknik yang digunakan secara nyata.

\section{Pendidikan Arsitektur dan Kreativitas}

Perguruan Tinggi sebagai Pusat Pengembangan Ilmu Pengetahuan, Teknologi dan Seni diharapkan dapat menghasilkan lulusan terdidik dan berbudaya sehingga dapat memelihara, melestarikan, mengembangkan dan mengaplikasikan ilmu serta teknologi bagi kesejahteraan umat manusia. Dalam melaksanakan kegiatan komponen yang terlibat langsung dalam pelaksanaan pendidikan tinggi antara lain: dosen, mahasiswa, kurikulum, silabi, laboratorium, workshop, perpustakaan serta fasilitas lain. Melalui interaksi akademik kegiatan memelihara, melestarikan, mengembangkan dan mengaplikasikan ilmu dan teknologi dilakukan.

Terdapat tiga alur pendidikan yang diselenggarakan di pendidikan tinggi yaitu akademik, profesional dan pendidikan profesi. Masing-masing memiliki kompetensi yang berbeda dalam penguasaan ilmu dan ketrampilan. Ketiga 
kompetensi tersebut secara proporsional diharapkan dapat mengisi kebutuhan bangsa dan negara dalam memajukan kesejahteraan masyarakat, mengisi pembangunan, mengembangkan ilmu pengetahuan serta hidup berdampingan sejajar dengan negara maju lain.

Setiap perguruan tinggi mamiliki otonomi dalam memberikan warna pendidikannya lewat kurikulum dan kegiatan-kegiatan akademik yang lain baik kurikuler maupun ekstrakurikuler. Dosen sebagai pelaksana akademik terdepan memiliki peran yang sangat menentukan dalam pemberian warna akademik lulusan. Dosen adalah figur utama yang selalu siap mengadakan tatap muka dengan para mahasiswa. Dengan demikian dosen diharapkan dapat memotivasi mahasiswa untuk mengembangkan kreatifitas yang tinggi yang merupakan prasyarat agar mahasiswa/lulusan dapat siap berkembang dan peka dalam menangkap peluang untuk mengembangkan profesinya.

Ciri-ciri seorang yang kreatif adalah luwes, tidak terikat pada informasi yang ada/tersedia, berani mengambil risiko, senang mencoba hal-hal baru, memiliki kemauan besar, senang bekerja keras, dan memiliki rasa humor yang tinggi. Dosen diharapkan dapat membina mahasiswa menjadi kreatif, sehingga di dalam tatap muka dengan mahasiswa tidak hanya dituntut dapat menjelaskan dan mendemonstrasikan apa-apa yang dikomunikasikan tetapi yang lebih penting ia harus dapat mengembangkan insprirasi mahasiswa pada hal-hal yang mungkin dapat dilakukan.

Materi kegiatan akademik tertentu dalam bentuk seminar, diskusi, lokakarya serta kunjungan lapangan merupakan kegiatan yang menarik yang memiliki nilai yang tinggi dalam mengembangkan inspirasi mahasiswa khususnya untuk penciptaan lapangan kerja yang baru. Pengalaman dan wawasan para dosen sangat menentukan dalam membina kegiatan semacam ini. Di lain pihak, mengundang dosen tamu, profesional serta praktisi dalam diskusi dengan mahasiswa secara periodik merupakan wahana yang sangat membantu.

\section{Kreativitas dan Pendidikan Arsitektur}

Dengan melihat model pengajaran, ada beberapa hal yang dapat dilakukan untuk mengembangkan strategi pengajaran dan belajar yang menunjang kreativitas. Pertama, perlu adanya suasana kompetitif, yang masih memungkinkan kerja sama. Dengan terbentuknya suasana kompetitif yang sehat, kreativitas akan lebih terpacu untuk tumbuh. Kedua, memang diperlukan ketersediaan fasilitas yang memungkinkan pengembangan, namun tidak semua hal harus disediakan. Adanya kendala dari sumberdaya yang ada terkadang justru dapat memicu loncatan kreatif untuk dapat menggunakan sarana-prasarana yang ada dengan cara yang lebih optimal.

Ketiga, teknik pengajaran yang tidak sekadar mengajarkan fakta dan pengetahuan, namun juga metode dan ketrampilan mengolah materi lebih lanjut dan dapat mengembangkan insprirasi mahasiswa pada hal-hal yang mungkin dapat dilakukan. Keempat, terbentuknya budaya akademis, yang tidak semata-mata 
mengembangkan kepandaian, namun juga emotional intelligence, keterampilan mengutarakan gagasan (communication skill), kemampuan menghargai orang lain dan bekerjasama dengan orang lain (get along with others), serta kemampuan untuk terus belajar dan mengembangkan diri (learning to learn). Kelima, selain terbentuknya budaya dan adanya suasana akademis yang sehat, juga diperlukan adanya suasana non-akademis yang kondusif terhadap munculnya gagasan-gagasan baru yang segar. Pendidikan yang bersifat "liberal" dengan tujuan meluaskan cakrawala peserta didik juga dapat meningkatkan keluasan memandang, yang dapat menggugah inspirasi untuk mengembangkan diri dan dunia kerja.

Teaching Style (Axclord):

- $\quad$ orientasi substansi (content-centered)

- $\quad$ orientasi pengajar (instructor centered)

- $\quad$ orientasi intelektual (intellect centered)

- $\quad$ orientasi personal (person centered)

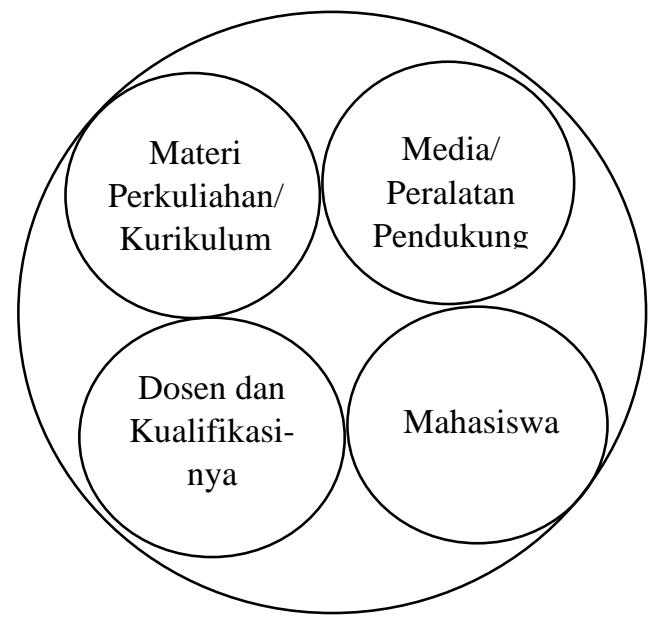

Learning Style (Grasha-Reichman):

- competitive vs. collaborative

- participative vs. avoidance

- independent vs. dependent

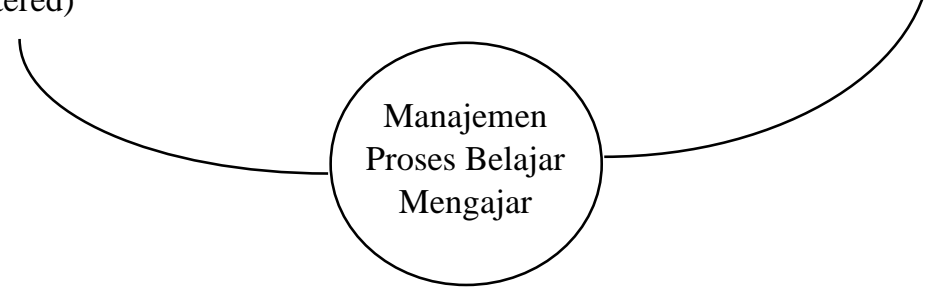

Gambar 1. Bagan manajemen proses belajar mengajar Sumber: Analisis penulis, 2020

\section{Tradisi dan Inovasi dalam Pendidikan Arsitektur}

Pada dasarnya arsitektur tidak dapat diajarkan, meski arsitektur dapat dipelajari dan dilatih. Meski ada beberapa kemampuan yang dapat diajarkan, yang meliputi (1) skills and dexterities: conditioning, demonstration, exercise; (2) judgmental capabilities: appropriateness, good-and-bad; (3) factual khowledge: materials, building codes; dan (4) knowledge of problems and the ways to go about them: consciousness.

Kualitas rancangan pada dasarnya dapat ditingkatkan dengan mempelajari preseden (precedents, karya arsitektur yang sudah ada dan dianggap berhasil) dan pemahaman yang lebih jauh mengenai prinsip-prinsip yang melandasi karya arsitektur tersebut (principles, gagasan-gagasan mengenai aspek-aspek yang 
menjadikan karya arsitektur berhasil dan mengenai implikasi guna dan citra terhadap karya arsitektur tersebut).

Sebagaimana para seniman kreatif lainnya, para arsitek menggunakan beberapa strategi yang lazim mereka lakukan dari waktu ke waktu. Mereka belajar melalui pengalaman, menyerap pelajaran pada tiap kasus perancangan, sehingga karya yang belakangan akan terpengaruh oleh karya-karya terdahulu. Oleh karena itu, seorang arsitek lazim dikaitkan dengan gaya dan langgam tertentu. Meski di sisi lain, karena ada hal-hal dan pengalaman-pengalaman baru yang diserap, maka gaya dan langgam sang arsitek tersebut juga mengalami perubahan-perubahan dari waktu ke waktu.

Di bidang seni dan desain, para pemula perlu belajar dengan memperhatikan bagaimana para pakar berkarya. Menggambarkan ulang dan meniru karya sang pakar secara sadar merupakan suatu tahap yang penting. Setelah memperhatikan dan meniru, diharapkan sang pemula dapat secara sadar menemukan prinsip-prinsip yang mendasari karya sang pakar tersebut. Pada akhirnya diharapkan sang pemula tersebut pada suatu saat dapat berkarya dengan strategi yang lebih sesuai dengan kemampuan dan kehendaknya.

Di bidang arsitektur, melalui preseden dapat dipelajari setidaknya tiga aspek:

1. aspek konseptual: filosofi dan gagasan yang mendasari karya

2. aspek programatis: fungsi dan hubungan antar fungsi

3. aspek formal: ruang dan bentuk

Secara konseptual, ada beberapa hal yang dapat dianalisis. Pertama, bagaimana implikasi konsep filosofis yang dimiliki sang arsitek di dalam karya rancangannya. Kedua, bagaimana cara sang arsitek merumuskan konsep rancangannya, yaitu gagasan yang dapat menyatukan berbagai elemen ke dalam kesatuan rancangan. Ketiga, bagaimana sang arsitek menanggapi tuntutan programatis, konteks, dan berbagai gagasan yang muncul.

Secara programatis, ada beberapa hal yang dapat dianalisis. Pertama, bagaimana sang arsitek membuat pemintakatan (zoning) atau pengelompokan fungsional. Kedua, bagaimana sang arsitek menata dan mengaitkan ruang pakai dengan ruang sirkulasi. Ketiga, bagaimana sang arsitek membentuk ruang dan massa dalam kaitannya dengan program dan fungsi yang harus diakomodasi.

Secara formal, ada dua hal yang dapat dianalisis. Pertama, analisis karya arsitektur sebagai konstruksi geometris (geometrical construction). Menganalisis karya arsitektur sebagai kumpulan raut, tatanan titik, garis, bidang, dan pertemuan bidang dalam ruang. Dalam hal ini, raut, bentuk, dan ruang dianalisis sebagai hasil serangkaian operasi geometris yang terkait dengan berbagai konsekuensi logisnya. Kedua, analisis karya arsitektur sebagai konfigurasi keruangan (spatial configuration). Karya arsitektur dibayangkan melalui pengalaman sejumlah ruang dan rangkaian pengalaman ketika seseorang berjalan di dalam bangunan, terutama melalui jalur tertentu atau pada bidang-bidang tertentu, yang memegang peranan penting dalam komposisi geometris. Kedua analisis ini perlu memenuhi 2 signifikansi. Pertama, kepuasan perolehan bentuk melalui abstraksi geometris 
tradisional dan kepuasan intelektual melalui penggunaan logika arsitektural. Ditambah dengan aspek yang kedua, yang boleh tercapai atau tidak tercapai, yaitu kesesuaian dengan fungsi.

Dalam suatu contoh tugas, mahasiswa diminta mempelajari desain rumah tinggal dengan menggambarkan kembali dan membuat model/maket. Menggambarkan ulang dan meniru karya arsitektur yang sudah ada dan dianggap berhasil secara sadar merupakan suatu cara belajar, agar mahasiswa dapat menemukan prinsipprinsip perancangan dari karya tersebut. Sambil menggambarkan atau membuat maketnya, diharapkan mahasiswa juga memikirkan/mencaritahu beberapa hal:

1. Apa tema desain pada karya tersebut, dan dari mana kira-kira sang arsitek memulai rancangannya?

2. Bagaimana sang arsitek meletakkan bidang, melubangi bidang, atau meneruskannya?

3. Bagaimana sang arsitek membentuk ruang, dan menghubungkan ruang?

4. Bagaimana sang arsitek membentuk massa, dan mengurangi/menambahnya?

5. Bagaimana sang arsitek mengelompokkan fungsi/kegiatan?

6. Bagaimana sang arsitek menggunakan prinsip-prinsip komposisi dalam rancangan tersebut?

Hal-hal inilah yang dapat dipresentasikan mahasiswa dalam display karyanya. Hal ini juga yang akan dapat membantu mahasiswa memahami hal-hal yang dapat digunakan untuk membantu meretas jalan kreativitas di satu sisi dan rasionalitas di sisi yang lain dalam perancangan. Memahami primary generator, mendalami gagasan konseptual, dan menerjemahkannya dalam gagasan programatik dan gagasan formal.

Tantangan kita sekarang adalah bagaimana hal-hal tersebut dapat dilakukan dengan baik, sementara interaksi dosen dan mahasiswa, termagang dan pemagang, menjadi terbatas karena adanya pandemi.

\section{Daftar Pustaka}

Haryana, Hatmoko, A.U. (1998). Pentingnya kreativitas dalam budaya akademis (Makalah disampaikan dalam Semiloka Reorientasi Manajemen Pendidikan Tinggi Kerjasama Ditjen Dikti - P3P LP3 UGM - UII, Yogyakarta, 29 Agustus 1998. Tidak dipublikasikan).

Hatmoko, A.U. (1997). Weaving heritage sites into larger context. Proceeding of $6^{\text {th }}$ Asia and West Pacific Network for Urban Conservation International Symposium.

Hatmoko, A.U. (1998) Creativity in conservation and development (Discussion Paper, Osaka Invitational Program for Short-term Overseas Trainees in Architecture and Arts, Osaka, Japan, October 23 ${ }^{\text {rd }}$, 1998. Tidak dipublikasikan).

Rowe, P.G. (1994). Design thinking, Massachusetts: The MIT Press. 